Hydroxyapatite Thin Films

\title{
Salt-Acid-Surfactant Lyotropic Liquid Crystalline Mesophases: Synthesis of Highly Transparent Mesoporous Calcium Hydroxyapatite Thin Films
}

\author{
Ebrima Tunkara ${ }^{[a]}$ and Ömer Dag*[a]
}

\begin{abstract}
Even though calcium hydroxyapatite $\left[\mathrm{Ca}_{10}\left(\mathrm{PO}_{4}\right)_{6}{ }^{-}\right.$ $\left.(\mathrm{OH})_{2}, \mathrm{HAp}\right]$ is one of the most investigated materials in the literature, the synthesis of mesoporous transparent thin film of HAp has not yet been reported. We show herein that mixtures of phosphoric acid $\left(\mathrm{H}_{3} \mathrm{PO}_{4} \cdot \mathrm{H}_{2} \mathrm{O}, \mathrm{PA}\right)$, calcium nitrate tetrahydrate $\left[\mathrm{Ca}\left(\mathrm{NO}_{3}\right)_{2} \cdot 4 \mathrm{H}_{2} \mathrm{O}, \mathrm{CaN}\right]$ and non-ionic surfactant $\left[\mathrm{C}_{12} \mathrm{H}_{25^{-}}\right.$ $\left(\mathrm{OCH}_{2} \mathrm{CH}_{2}\right)_{10} \mathrm{OH}, \mathrm{C}_{12} \mathrm{E}_{10}$ ] can self-assemble into stable lyotropic liquid crystalline (LLC) mesophases. The clear aqueous solutions of the mixtures can be spin-coated over any substrate and then calcined to form highly transparent mesoporous HAp (mHAp)
\end{abstract}

thin films. From among the compositions studied, three molar ratios of $\mathrm{CaN} / \mathrm{PA} / \mathrm{C}_{12} \mathrm{E}_{10}$ [3.3:2:1 (low), 5.8:3.5:1 (intermediate) and 8.4:5:1 (high)] were chosen for large-scale preparation to investigate their structural and thermal properties. The mHAp films form at around $300{ }^{\circ} \mathrm{C}$ and fully crystalize at $500{ }^{\circ} \mathrm{C}$, retaining their transparency, uniformity and porosity in all compositions with few differences. The surface area and pore volume decrease, and the pore size and pore size distribution increase with increasing annealing temperature for all compositions.

\section{Introduction}

Many salts with low melting points and/or high solubility in aqueous media form stable lyotropic liquid crystalline (LLC) mesophases with non-ionic surfactants. ${ }^{[1,2]}$ In this assembly process, the salt species in the hydrophilic domains of the LLC mesophase melt at relatively low temperatures or dissolve in smaller amounts of water. It is also known that the melting points of the salts further decrease $\mathrm{e}^{[1]}$ and their water solubility is enhanced ${ }^{[2]}$ when they are confined within the hydrophilic domains of the mesophase. This confinement in nanoscale space is known as the soft confinement effect (SCE). ${ }^{[3-6]}$ In these assemblies, the metal ions have either a hydration sphere or are coordinated by water coordination. ${ }^{[1,2]}$ For instance, aqua complexes of most first-row and some second-row transition metals undergo self-organization with non-ionic surfactants into various mesostructures. ${ }^{[7]}$

The decrease in the melting point and increase in the solubility can also be considered to be due to deliquescence relative humidity $(\mathrm{DRH})$, which is known to be responsible for species self-dissolving by absorbing ambient water at room temperature. Therefore many salts and highly hygroscopic chemical species either melt or dissolve and cooperatively self-assemble with non-ionic surfactants [such as oligo(ethylene oxides) and pluronics] to form stable LLC mesophases. ${ }^{[1,2,7,8]}$ Both $\mathrm{H}_{3} \mathrm{PO}_{4}$ and $\mathrm{Ca}\left(\mathrm{NO}_{3}\right)_{2} \cdot 4 \mathrm{H}_{2} \mathrm{O}$ have very low melting points and they

\footnotetext{
[a] Department of Chemistry, Bilkent University,

06800 Ankara, Turkey

E-mail: dag@fen.bilkent.edu.tr

http://www.fen.bilkent.edu.tr/ dag/

$\square$ Supporting information for this article is available on the WWW under http://dx.doi.org/10.1002/ejic.201501116.
}

spontaneously absorb water and dissolve under ambient conditions. This makes them important candidates as non-volatile solvents for the self-assembly of non-ionic surfactants in the design of new porous materials. ${ }^{[9,10]}$ Some alkali and alkalineearth metal salts such as $\mathrm{Ca}\left(\mathrm{NO}_{3}\right)_{2}, \mathrm{CaCl}_{2}, \mathrm{MgCl}_{2}$ and $\mathrm{LiX}(\mathrm{X}=$ $\left.\mathrm{Cl}^{-}, \mathrm{Br}^{-}, \mathrm{I}^{-}, \mathrm{NO}_{3}{ }^{-}\right)$, and likely many more, can also be effectively hydrated and dissolved in a very small volume of water to form stable mesophases.

Calcium hydroxyapatite $\left[\mathrm{Ca}_{10}\left(\mathrm{PO}_{4}\right)_{6}(\mathrm{OH})_{2}\right.$, abbreviated as HAp] is one of the most promising materials in bone and tissue engineering because of its osteoconductivity, non-inflammatory, non-toxicity, compatibility and ability to replace worn-out tissues. ${ }^{[11]}$ These properties make HAp a good candidate for use in drug and protein delivery systems as well as in other medical applications. ${ }^{[12-19]}$ Synthesized HAp comes in two forms: porous or dense. The former has attracted more attention from researchers because of the large surface area. In addition to surface area, the size and volume of the pores are also important features to consider when synthesizing this material. So far, reported synthetic techniques include sol-gel synthesis, emulsion techniques, a mixed surfactant-mediated approach, low-temperature hydrothermal processes, precipitation and hydrolysis. ${ }^{[12-34]}$ Despite numerous synthetic techniques, few attempts to synthesize mesoporous thin films have been reported. ${ }^{[35]}$ Instead, most of the aforementioned techniques result in the production of HAp powders with small surface areas and hollow nanospheres. ${ }^{[34]}$ The major challenge in these synthetic methods is the fast precipitation/crystallization of calcium phosphate species. ${ }^{[34]}$ Some of these synthetic methods also involve LLC templating ${ }^{[35-38]}$ but the calcium ion concentrations used in those investigations were too low to obtain films or monoliths of HAp and as a result led to the production of small quantities 
of apatite in the gel phase. ${ }^{[35-38]}$ To the best of our knowledge, uniform and transparent thin films of mesoporous apatite have not yet been prepared. The synthesis of uniform mesoporous HAp films over various substrates could be very important not only in bone and tissue implantation, but also in the creation of inert surfaces for cell proliferation and other biological applications. Note also that pores larger than $10 \mathrm{~nm}$ are useful for the delivery of proteins, genes and large-molecule drugs, with smaller pores being suitable for the delivery of smaller drug molecules. ${ }^{[39]}$

In this investigation, we show that calcium nitrate and phosphoric acid in the presence of non-ionic surfactants can selfassemble into stable LLC mesophases that can be calcined at higher temperatures to produce sponge-like $\left(L_{3} \text { phase }\right)^{[40]}$ highly transparent mHAp thin films. The mesophases and resulting mHAp films were characterized by SEM, TEM, $\mathrm{N}_{2}$ sorption, FTIR and Raman spectroscopy and PXRD and electron diffraction (ED) techniques.

\section{Results and Discussion}

A non-ionic surfactant such as $\mathrm{C}_{12} \mathrm{H}_{25}\left(\mathrm{OCH}_{2} \mathrm{CH}_{2}\right)_{10} \mathrm{OH}\left(\mathrm{C}_{12} \mathrm{E}_{10}\right)$ forms stable liquid crystalline mesophases with $85 \%$ phosphoric acid $\left(\mathrm{H}_{3} \mathrm{PO}_{4} \cdot \mathrm{H}_{2} \mathrm{O}, \mathrm{PA}\right){ }^{[41]}$ pure calcium nitrate tetrahydrate $\left[\mathrm{Ca}\left(\mathrm{NO}_{3}\right)_{2} \cdot 4 \mathrm{H}_{2} \mathrm{O}, \mathrm{CaN}\right]^{[42]}$ and a mixture of the two. The $\mathrm{PA}-\mathrm{C}_{12} \mathrm{E}_{10}$ mesophases are stable over a very broad range of $\mathrm{PA} /$ $\mathrm{C}_{12} \mathrm{E}_{10}$ molar ratios (2 to 20 ) and temperatures ( -30 to $130{ }^{\circ} \mathrm{C}$ ). The $\mathrm{CaN}-\mathrm{C}_{12} \mathrm{E}_{10}$ mesophases are also stable over a wide range of $\mathrm{CaN}$ concentrations. Note also that both the PA-C $\mathrm{C}_{12} \mathrm{E}_{10}$ and $\mathrm{CaN}-\mathrm{C}_{12} \mathrm{E}_{10}$ mesophases are cubic at high $\mathrm{PA} / \mathrm{C}_{12} \mathrm{E}_{10}$ and $\mathrm{CaN} /$ $\mathrm{C}_{12} \mathrm{E}_{10}$ molar ratios. ${ }^{[41,42]}$ In this work we focussed on the LLC mesophase of a mixture of $\mathrm{PA}, \mathrm{CaN}$ and $\mathrm{C}_{12} \mathrm{E}_{10}$, and its transformation into mesoporous HAp (mHAp). Clear aqueous solutions of the constituents can be prepared over a very broad concentration range of $\mathrm{PA}$ and $\mathrm{CaN}$ and are stable for months; there is no precipitation of calcium phosphate species due to the high acidity of the media. The solutions can be spin-coated over any substrate. During the coating process, the excess water quickly evaporates and leaves behind a mesophase of the PA-CaN$\mathrm{C}_{12} \mathrm{E}_{10}$ mixture with a very small amount of water. In this assembly process, the CaN and PA collectively act as a solvent to induce the self-assembly of the surfactant into an LLC mesophase. The mesophase is also stable on the substrate for days at room temperature due to the acidity of the media, which prevents the precipitation of the calcium phosphate species.

No definite solid transformation was observed during the aging process at room temperature. However, there were some changes in the media during the aging of the gel-like films (for details see the FTIR section). Figure 1 shows a schematic representation of the LLC mesophase and $\mathrm{mHAp}$ after the transformation. The LLC phase is ordered (diffracts at small angles) up to a $\mathrm{CaN} / \mathrm{PA} / \mathrm{C}_{12} \mathrm{E}_{10}$ molar ratio of 8.4:5:1. In this investigation we studied compositions with molar ratios between 2.5:1.5:1 and 8.4:5:1 CaN/PA/ $\mathrm{C}_{12} \mathrm{E}_{10}$. The ratio of calcium to phosphate was always maintained at $1.67\left(\mathrm{Ca}^{2+} / \mathrm{PO}_{4}{ }^{3-}\right.$ ratio in the $\left.\mathrm{HAp}\right)$ in all compositions. Note also that these concentrations are high enough to produce thick pore walls that can resist calcination during the formation of the mesoporous network (see Figure 1).
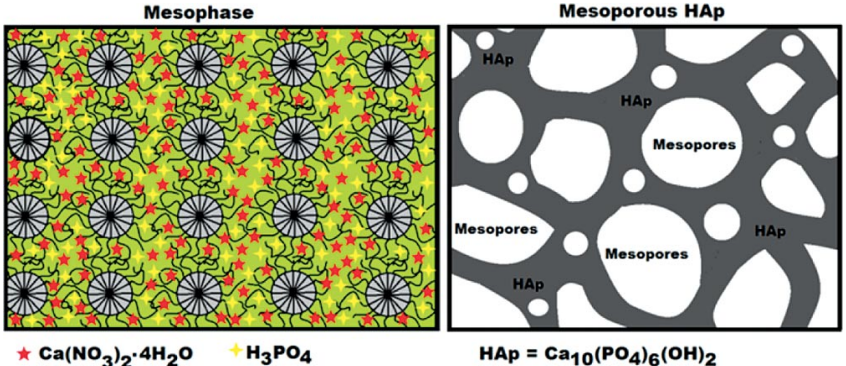

Figure 1. Schematic representation of the LLC mesophase (left) and mesoporous HAp (right).

Figure 2 (a) shows a series of small-angle powder X-ray diffraction patterns collected from various thin films of the fresh samples. The small-angle diffraction line observed at a $2 \theta$ value of between 1.7 and $2.0^{\circ}$ ( $d$ spacing $52-44 \AA$ ) is due to the LLC mesophase. The observed single line makes it difficult to predict the structure of the mesophase. However, the thicker samples are dark between the cross polarizers under a polarized optical microscope (POM), which, collectively, suggests that the mesophase is cubic, similarly to the individual phases $\left(P A-C_{12} E_{10}\right.$ and $\mathrm{CaN}-\mathrm{C}_{12} \mathrm{E}_{10}$ ). Another diffraction line is observed at around $7.50^{\circ}$ (d spacing $11.8 \AA$ ) owing to the presence of $\mathrm{CaHPO}_{4} \cdot 2 \mathrm{H}_{2} \mathrm{O}$ or $\mathrm{Ca}\left(\mathrm{H}_{2} \mathrm{PO}_{4}\right)_{2} \cdot \mathrm{H}_{2} \mathrm{O}$ in the freshly prepared samples. However, this line disappears over time, which indicates the complete solubility of the calcium species in the LLC media (see Figure 2,

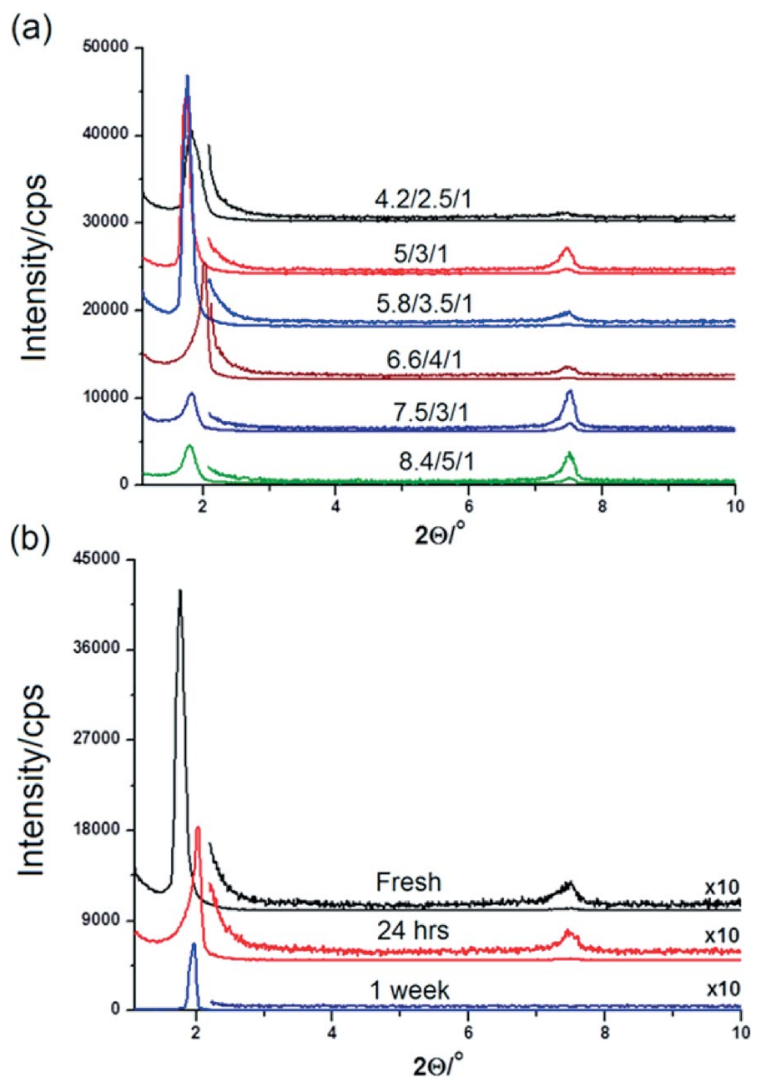

Figure 2. PXRD patterns of fresh gel thin films of CaN-PA- $\mathrm{C}_{12} \mathrm{E}_{10}$ with the CaN/ $P A / C_{12} E_{10}$ molar ratio in the range of 3.3:2:1 to 8.4:5:1 (a) and after aging for up to 1 week (b), as indicated on the plots. 
b) and can be attributed to both the high solubility of the ionic species in a confined space ${ }^{[2]}$ and the high acidity of the media. As shown in Figure 1, the acid and calcium salt species are evenly distributed in the hydrophilic region of the mesophase and are ready to form calcium phosphate species. Note also that the diffraction patterns do not show much response to an increase in the aqueous species in the hydrophilic domains. It is already known from the salt-surfactant system that increasing the salt/surfactant ratio expands the unit cell of the mesophase to accommodate more salt species. ${ }^{[43]}$ Therefore, the new behaviour (no change in the unit cell) can be interpreted as a decrease in the aggregation number of the surfactant, that is, the number of surfactants per unit volume, in the mesophase to accommodate more aqueous species per surfactant. Therefore, the content of the hydrophilic domains likely does not change much with increasing aqueous species in the media.

To further elucidate the nature of the species in the LLC media, we also recorded FTIR spectra of fresh samples with different compositions and during the aging process (Figure 3 ). Note that the peaks relating to the PA and nitrate gradually increase with increasing $\mathrm{CaN}$ and PA content in the samples (Figure 3, a). The peaks at around 2340 and $2930 \mathrm{~cm}^{-1}$ are characteristic of PA and arise from symmetric and anti-symmetric $\mathrm{v}-\mathrm{OH}$ modes. $^{[44-46]}$ The high frequency broad peak at around $3560 \mathrm{~cm}^{-1}$ is also characteristic of the free (non-hydrogen bonding) $\mathrm{OH}$ moiety of $\mathrm{H}_{3} \mathrm{PO}_{4} \cdot{ }^{[44-46]}$ The other broad features at around $3200-3500 \mathrm{~cm}^{-1}$ are due to the free and coordinated water molecules around the ions. The peak at around
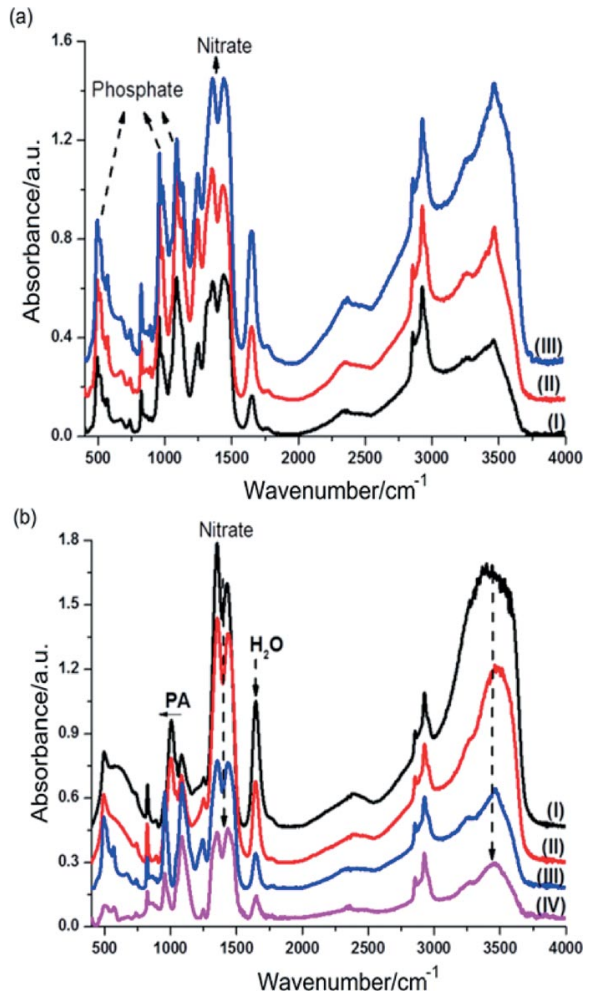

Figure 3. (a) FTIR spectra of fresh samples with $\mathrm{CaN} / \mathrm{PA} / \mathrm{C}_{12} \mathrm{E}_{10}$ molar ratios of (I) 4.2:2.5:1, (II) 5.8:3.5:1 and (III) 7.5:4.5:1. (b) FTIR spectra of a fresh sample of 8.4:5:1 CaN/PA/ $\mathrm{C}_{12} \mathrm{E}_{10}$ recorded at room temperature over time: (I) immediately, (II) $10 \mathrm{~min}$, (III) $60 \mathrm{~min}$ and (IV) 1 week.
$1003 \mathrm{~cm}^{-1}$, and its high frequency shoulder in the pure PA, shifts to $956 \mathrm{~cm}^{-1}$.

Many changes can be observed in the spectra during the aging process; the water peak at $1640 \mathrm{~cm}^{-1}$ and the nitrate related peaks ${ }^{[47]}$ at $1045,1296,1370$ and $1490 \mathrm{~cm}^{-1}$ lose intensity, whereas new peaks emerge at 493, 520, 544, 568, 855, 956 and $1130 \mathrm{~cm}^{-1}$ (see Figure 3, b). These peaks are well resolved and quite sharp, indicating that they originate from crystalline phosphate species. The spectral changes also reveal that huge amounts of water and nitrates are eliminated from the media as water vapour and likely nitric acid, respectively. The evaporation of both water and nitric acid enhances the formation of the calcium phosphate type species. ${ }^{[44-46]}$ Because we could identify the presence $\mathrm{CaHPO}_{4} \cdot 2 \mathrm{H}_{2} \mathrm{O}$ or $\mathrm{Ca}\left(\mathrm{H}_{2} \mathrm{PO}_{4}\right)_{2} \cdot \mathrm{H}_{2} \mathrm{O}$ in the PXRD pattern, these spectral changes can be attributed to the formation of those phosphates in the freshly prepared samples. ${ }^{[45]}$ The FTIR spectral changes also confirm that these species re-dissolve over time and many sharp peaks disappear from the spectra (compare spectra III and IV in Figure 3, b). However, the samples are gel-like and stable for months without achieving the complete formation of calcium phosphate or calcium hydroxyapatite. It is likely that the formation of insoluble phosphate species is hindered, because the media is still quite acidic.

For further investigations we chose three different compositions of $\mathrm{CaN}-\mathrm{PA}-\mathrm{C}_{12} \mathrm{E}_{10}$ to prepare in large quantities [denoted as low (3.3:2:1 $\mathrm{CaN} / \mathrm{PA} / \mathrm{C}_{12} \mathrm{E}_{10}$ molar ratio, sample $\mathrm{A}$ ), intermediate (5.8:3.5:1 $\mathrm{CaN} / \mathrm{PA} / \mathrm{C}_{12} \mathrm{E}_{10}$ molar ratio, sample $\mathrm{B}$ ) and high (8.4:5:1 CaN/PA $/ \mathrm{C}_{12} \mathrm{E}_{10}$ molar ratio, sample C)]. Around 150-200 glass slides were coated using the clear solutions of these three compositions. The samples were then calcined at various temperatures and analysed by FTIR spectroscopy, PXRD, $\mathrm{N}_{2}$-sorption measurements and TEM. Figure 4 shows the variation in the FTIR spectra upon heating sample $A$. The surfactant-related peaks remain, with only some small changes, up to $250{ }^{\circ} \mathrm{C}$, but completely disappear at around $300{ }^{\circ} \mathrm{C}$. The remaining broad peaks, observed at 575, 951 and $1061 \mathrm{~cm}^{-1}$, are characteristic of calcium hydroxyapatite. ${ }^{[48]}$ The peaks at 569, 600 and $632 \mathrm{~cm}^{-1}$ are due to phosphate and hydroxide bending modes, and those (a)

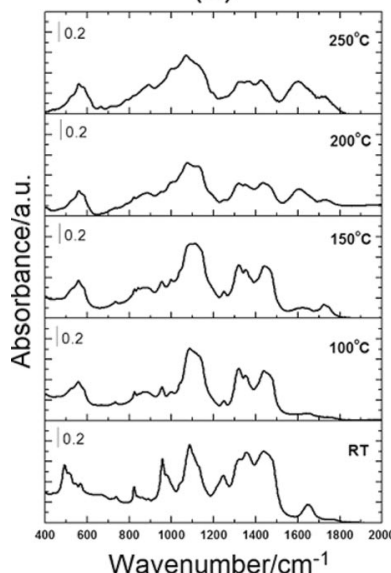

Wavenumber/cm-1 (b)

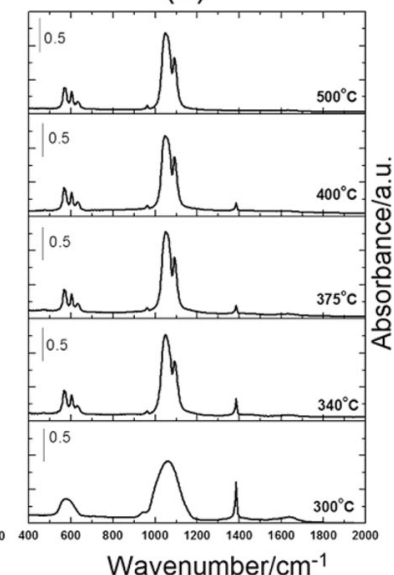

Figure 4. FTIR spectra of sample $A$ at different temperatures (as indicated on the spectra): (a) on a Si wafer (low temperature) and (b) in $\mathrm{KBr}$ pellets of a powder sample (high temperatures). 
at 960,1046 and $1091 \mathrm{~cm}^{-1}$ are due to phosphate stretching modes. A new sharp peak also appears at $3574 \mathrm{~cm}^{-1}$ due to the stretching mode of the $\mathrm{OH}$ groups of the hydroxyapatite. ${ }^{[46]}$ The HAp-related peaks first appear at $300{ }^{\circ} \mathrm{C}$ and become sharper and well resolved at higher temperatures. However, the nitrate- and likely carbonate-related peaks are also weakly observed at this stage and they completely disappear at around $500{ }^{\circ} \mathrm{C}$ (see $1200-1600 \mathrm{~cm}^{-1}$ region). The sharp peak at around $1384 \mathrm{~cm}^{-1}$ is due to crystalline $\mathrm{KNO}_{3}$, which forms when nitratecontaining samples are pressed into $\mathrm{KBr}$ pellets. As shown in the spectra, this peak gradually disappears with increasing annealing temperature. No additional changes were observed upon further heating to $500{ }^{\circ} \mathrm{C}$. The samples $\mathrm{B}$ and $\mathrm{C}$ display similar spectral changes upon annealing at different temperatures (see Figure S1 in the Supporting Information). Therefore, a simplified overall reaction is given by Equation (1).

$10 \mathrm{Ca}\left(\mathrm{NO}_{3}\right)_{2}+6 \mathrm{H}_{3} \mathrm{PO}_{4}+2 \mathrm{H}_{2} \mathrm{O} \rightarrow \mathrm{Ca}_{10}\left(\mathrm{PO}_{4}\right)_{6}(\mathrm{OH})_{2}+20 \mathrm{HNO}_{3}$

Note also that many methods reported in the literature use basic media for the precipitation of calcium hydroxyapatite. Here, we have shown for the first time that a highly acidic media and heat treatment can also be used to synthesize mHAp. The likely byproduct of the annealing process is nitric acid and/ or its decomposition products, produced during calcination and further annealing steps. The calcined films are of high quality, crack free and highly transparent up to $500{ }^{\circ} \mathrm{C}$ and become opaque at around $600{ }^{\circ} \mathrm{C}$ (see Figure 5).

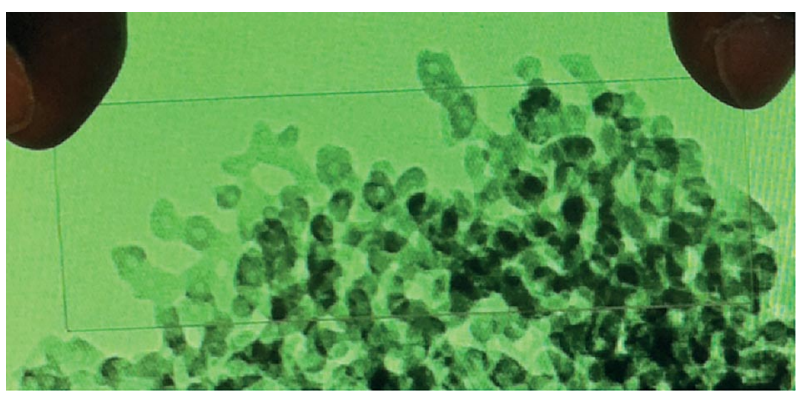

Figure 5. Photograph of a transparent mesoporous HAp thin film coated upon a microscope slide.

Around $150-200$ transparent films were prepared on glass slides, calcined at $300{ }^{\circ} \mathrm{C}$ and then scraped from the glass surface, to collect around $60 \mathrm{mg}$ of powder samples for the PXRD and $\mathrm{N}_{2}$-sorption measurements. The PXRD and $\mathrm{N}_{2}$-sorption measurements were carried out at 300,400 and $500{ }^{\circ} \mathrm{C}$ using the same powder samples. Figure 6 and Figure S2 in the Supporting Information show the PXRD patterns of powder samples $A, B$ and $C$ at those three temperatures. Clearly, all the diffraction lines correspond to calcium hydroxyapatite (by comparison with the ICDD PDF card \#01-074-0566). The only change in the PXRD patterns is that the lines become sharper and well resolved with increasing annealing temperature, which indicates the growth and/or further crystallization of the calcium hydroxyapatite pore walls (see TEM analysis below). For all compositions we obtained HAp with slightly different crystallinity. For instance, sample $\mathrm{C} 300$ (prepared at $300{ }^{\circ} \mathrm{C}$ using sample $\mathrm{C}$ with the highest $\mathrm{CaN}$ and PA molar ratio of 8.4:5) displays

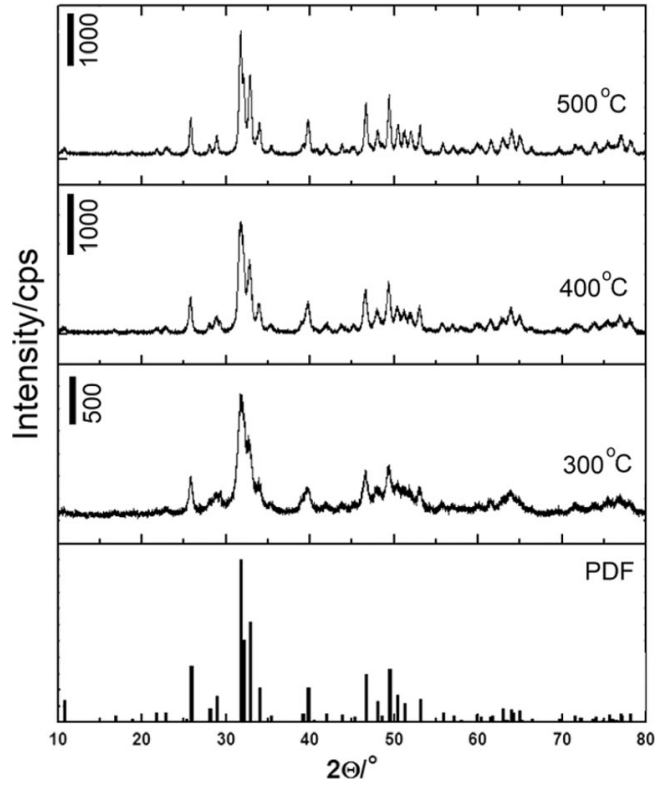

Figure 6. PXRD patterns of $A 300, A 400$ and $A 500\left(\mathrm{CaN} / \mathrm{PA} / \mathrm{C}_{12} \mathrm{E}_{10}\right.$ molar ratio of $3.4: 2: 1$ ) at three different temperatures (as marked on the patterns; bottom pattern is the PDF card \#01-074-0566 in the ICDD database).

broader diffraction lines, but it also fully crystallizes upon heating at $500{ }^{\circ} \mathrm{C}$ (see Figure S2). Figure 7 and Figure S3 show the $\mathrm{N}_{2}$-sorption isotherms of samples A, B and C calcined at 300, 400 and $500{ }^{\circ} \mathrm{C}$. Clearly, all the isotherms are type IV isotherms, characteristic of mesoporous materials, and show hysteresis. The BET surface area of sample A changes from 96 to $24 \mathrm{~m}^{2} / \mathrm{g}$ upon increasing the calcination temperature from 300 to $500{ }^{\circ} \mathrm{C}$. The $\mathrm{BJH}$ pore-size distribution plots, from desorption branches, peak at $20 \mathrm{~nm}$ (with a shoulder at $13 \mathrm{~nm}$ ) and $25.3 \mathrm{~nm}$ for $\mathrm{A} 300$ and A400, respectively. However, the poresize distribution plot of $A 500$ shows a weak and sharp feature at $3.0 \mathrm{~nm}$ and a weak and very broad feature at around $42 \mathrm{~nm}$. The pore volume of sample $A$ follows the trend in pore size, with values of $0.58,0.40$ and $0.08 \mathrm{~cm}^{3} / \mathrm{g}$ at 300,400 and $500{ }^{\circ} \mathrm{C}$, respectively. Similar changes were observed for samples $B$ and C. The $\mathrm{N}_{2}$-sorption data for the other compositions are given in Table 1 (see also Figures S3 and S4 for detail). The pore-size distribution plots display a dependence on the composition (at $300{ }^{\circ} \mathrm{C}$ ) and both $\mathrm{A} 300$ and $\mathrm{B} 300$ show two features (see the TEM image in Figures 5, 7; see also Figure S4C in the Supporting Information), whereas C 300 has a uniform pore-size distribution and peaks at around $12 \mathrm{~nm}$. Note also that the PXRD pattern of C300 displays much broader diffraction lines than A300 and B300 (compare the PXRD patterns in Figure 6 and Figure S2). It is likely that C300 has thinner pore walls or lower crystallinity than samples A300 and B300. However, for all compositions the pore size increases and displays a broad distribution upon heating at $400{ }^{\circ} \mathrm{C}$, but the surface area and pore volume decrease with further heating, whereas the pore size distribution becomes extremely broad. Both the PXRD and $\mathrm{N}_{2}$-sorption data are consistent and provide information regarding the mesoporous walls that increase in size and crystallize upon heating at higher temperatures and collapse at around $600{ }^{\circ} \mathrm{C}$ (also see the TEM analysis). 

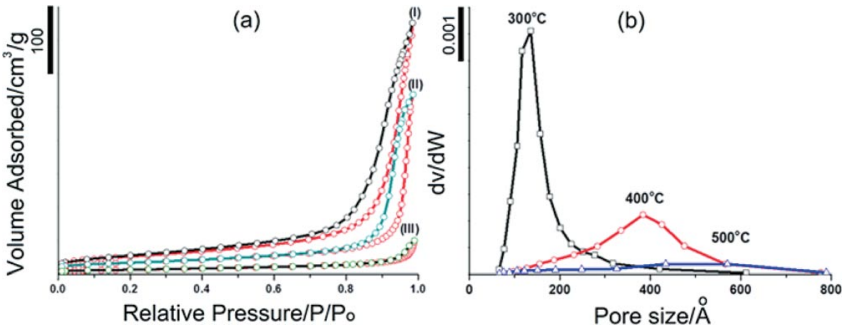

Figure 7. (a) $\mathrm{N}_{2}$ sorption (77 K) isotherms of (I) $\mathrm{A} 300$, (II) A400 and (III) A500 and (b) pore-size distribution plots for $\mathrm{C} 300, \mathrm{C} 400$ and $\mathrm{C} 500$ (temperatures are marked in the plots).

Table 1. $\mathrm{N}_{2}$ sorption data of HAp prepared at three different compositions.

\begin{tabular}{lcccc}
\hline Sample & $T^{[\mathrm{a}]}\left[{ }^{\circ} \mathrm{C}\right]$ & $\mathrm{SA}^{[\mathrm{b}]}\left[\mathrm{m}^{2} / \mathrm{g}\right]$ & $\mathrm{PV}^{[\mathrm{c}]}\left[\mathrm{cm}^{3} / \mathrm{g}\right]$ & $\mathrm{PS}^{[\mathrm{d}]}[\mathrm{nm}]$ \\
\hline $\mathrm{A}$ & 300 & 96 & 0.58 & $13 / 20$ \\
& 400 & 61 & 0.40 & 25.3 \\
$\mathrm{~B}$ & 500 & 24 & 0.08 & 42 \\
& 300 & 86 & 0.58 & $12 / 27$ \\
& 400 & 40 & 0.26 & 40 \\
$\mathrm{C}$ & 500 & 26 & 0.10 & 25 \\
& 300 & 78 & 0.40 & 12.4 \\
& 400 & 36 & 0.27 & 38.4 \\
& 500 & 23 & 0.10 & $30-60$
\end{tabular}

[a] $T=$ calcination temperature. [b] SA $=$ BET surface area. [c] PV $=$ BJH pore volume from desorption branch. [d] PS $=\mathrm{BJH}$ pore size from desorption branch.

To further verify the formation of mHAp, a series TEM images were collected at three different temperatures. Figure 8 (a) shows a large-area image of the film of sample A350. Figure 8 $(b, c)$ show higher resolution images; the porous network is clearly seen with an average pore-wall thickness of around $6.0 \mathrm{~nm}$. The selected area electron diffraction (SAED) pattern shown in the inset of Figure 8 (c) shows the crystalline nature
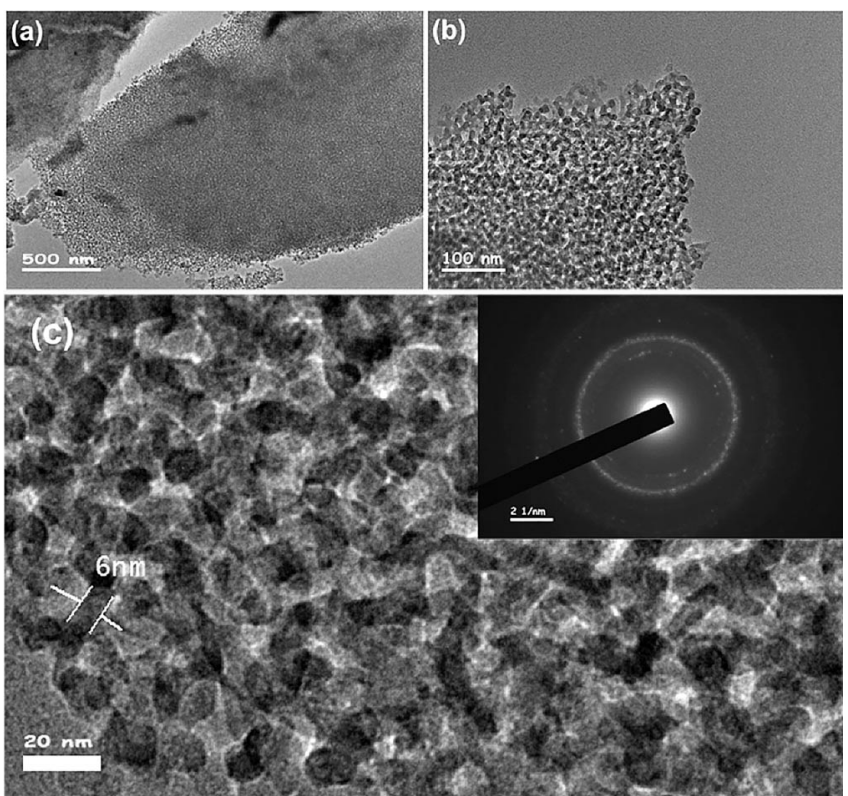

Figure 8. (a-c) TEM images of thin film of mHAp A350 at different magnifications. Inset to (c): SAED image. of the pore walls. With further heating, the pore walls grow and further crystallize, as observed in the PXRD (shown in Figure 6) and SAED patterns and high-resolution TEM images. The thickness of the pore walls increases to around $20 \mathrm{~nm}$ at $500{ }^{\circ} \mathrm{C}$, retaining a sponge-like porosity (Figure 9, a). Therefore, it is reasonable to observe such a decrease (from 96 to $24 \mathrm{~m}^{2} / \mathrm{g}$ ) in the surface area.
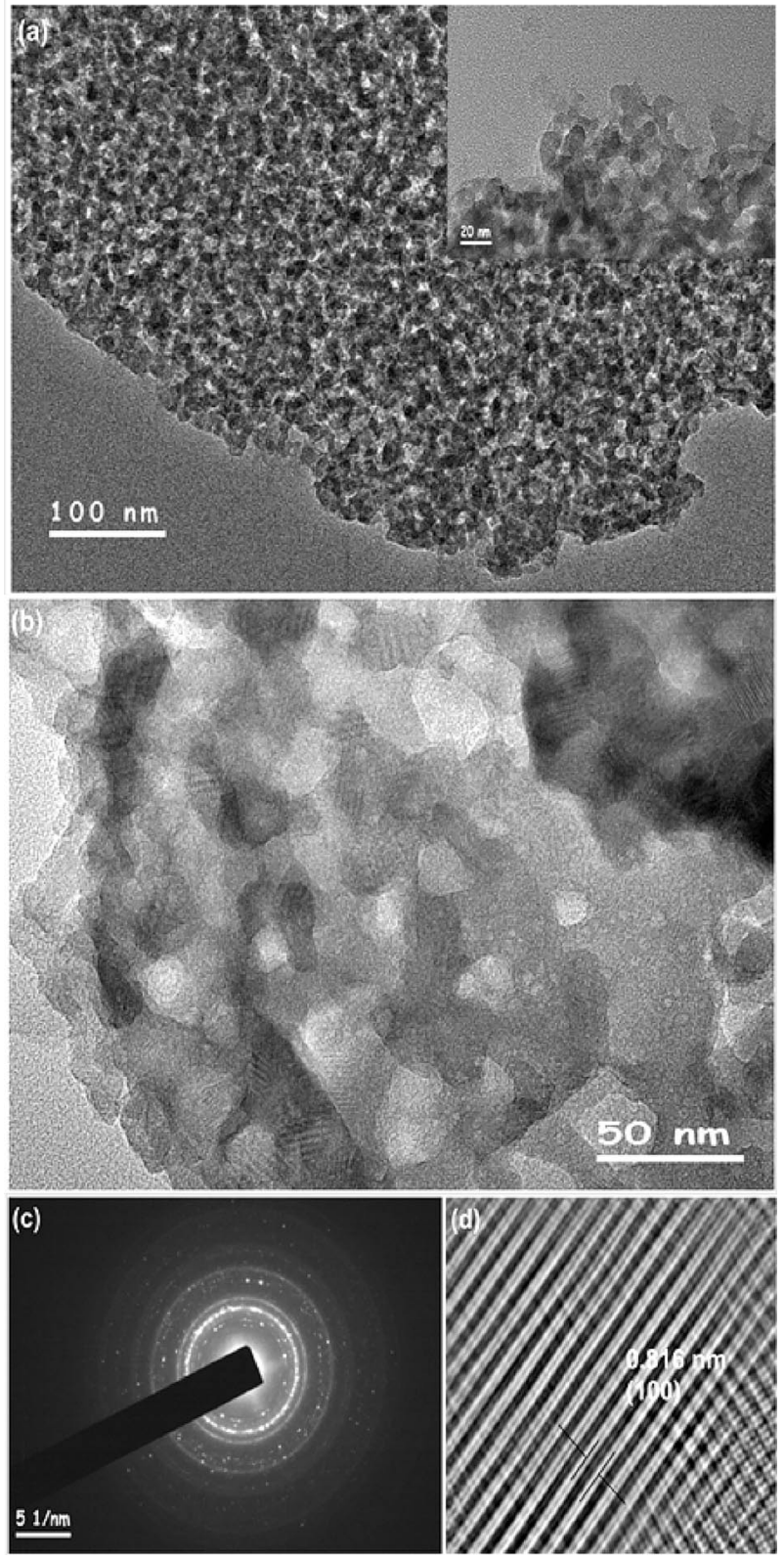

Figure 9. TEM images of mHAp films of sample A calcined at (a) $500^{\circ} \mathrm{C}$ (inset: enlarged domains on the edge of the film) and (b) $600{ }^{\circ} \mathrm{C}$. (c) SAED pattern of A600. (d) Fast Fourier transformed (FFT), masked and then back FFT images from a selected area in panel (b).

The TEM images of the samples calcined at $600{ }^{\circ} \mathrm{C}$ still show some porous domains as well as larger crystallites $(20-30 \mathrm{~nm}$, see Figure 9, b). Further annealing enhances the crystallinity of the samples (compare SAED patterns in inset to Figure 8 (c) and 
Figure 9, c). However, these samples are quite opaque due to the formation of larger crystallites and multiple cracks in the film. The high-resolution images of the crystalline pore walls were further analysed to prove that the walls are calcium hydroxyapatite. Figure 9 (d) displays an inverse fast Fourier transform (FFT) image of a selected area in Figure 9 (b), masked and back FFT, that clearly displays lattice fringes with a spacing of $0.816 \mathrm{~nm}$, which corresponds to the (100) plane of the hexagonal $\mathrm{Ca}_{10}\left(\mathrm{PO}_{4}\right)_{6}(\mathrm{OH})_{2}$. Some of the other common planes of HAp have also been evaluated by using these high-resolution TEM images. All the techniques employed in this investigation (SAED, PXRD, TEM, $\mathrm{N}_{2}$ sorption and FTIR) collectively show that the films are mesoporous and the pore walls are formed from pure and crystalline calcium hydroxyapatite.

The TEM images of samples B and C clearly display two pore systems at low temperatures. Figure S5 in the Supporting Information shows small and large pores in sample B350, with the small pores predominating over large pores in sample C350. Overall, the images clearly show the spongy $\mathrm{L} 3$ phase of mHAp. These results are also consistent with the $\mathrm{N}_{2}$-sorption data. Note that the pores, both small and large, are much larger than the typical micelle domain size of the LLC mesophase. It is likely that, at higher temperatures, not only the mesophase undergoes many changes, but the thinner pore walls collapse to yield thicker pore walls and create larger pores. The major reason for this must be the large change in the PA-CaN composition in the hydrophilic domains of the mesophase upon transformation to HAp during calcination. This is a reasonable explanation because sample $C$ has the largest PA and $\mathrm{CaN}$ composition, but the smallest pores at low temperatures. Altogether, it is reasonable to suggest that at low concentrations the pore walls crystallize and grow at the expense of the collapse of the smaller pores, but at higher temperatures all the compositions produce more or less similar sponge-like mesoporous films.

\section{Conclusions}

Calcium nitrate and phosphoric acid can be dissolved in aqueous media in the presence of $\mathrm{C}_{12} \mathrm{E}_{10}$, a non-ionic surfactant, to obtain clear solutions that can be spin-coated onto any substrate to form lyotropic liquid crystalline thin films. The mixtures in the solution phase stay stable as clear solutions indefinitely at room temperature, without undergoing precipitation. However, the LLC thin films undergo some changes, but remain as gels for months for all compositions. During calcination, the ordered LLC phase undergoes structural changes and by the time the mesostructure solidifies, the mesophase becomes a sponge-like $L_{3}$ phase ${ }^{[40]}$ and produces sponge-like $\mathrm{mHAp}$ for all compositions. The calcination could be carried out between 300 and $500{ }^{\circ} \mathrm{C}$ to obtain transparent mHAp films. The pore size (12-42 nm), pore volume (0.58-0.08) and wall thickness (6$20 \mathrm{~nm}$ ) can be adjusted by controlling the calcination temperature. Compositional changes have smaller effects on these parameters. All compositions, from low $\mathrm{CaN}$ and PA concentrations (sample A) to very high $\mathrm{CaN}$ and PA concentrations (sample C), produced similar materials. It is likely that by increasing the concentrations of $\mathrm{CaN}$ and PA in the media, the aggregation number of the surfactant in the mesophase decreases to produce a similar mesophase and, as a result, similar pore structures are observed in all compositions upon calcination.

The salt/phosphoric acid/ $\mathrm{C}_{12} \mathrm{E}_{10}$ mesophase is an important synthetic route for the synthesis of mHAp thin films and this work is the first example of the use of acid and salt in the same LLC media. Note also that many transition-metal nitrates also form LLC mesophases with non-ionic surfactants. ${ }^{[7,8]}$ Therefore, incorporating phosphoric acid and a transition-metal nitrate salt into LLC mesophases may be beneficial for producing many other mesoporous metal phosphate thin films for use in various energy applications.

\section{Experimental Section}

Materials: All chemicals were purchased from Sigma-Aldrich and used without further treatment. Fresh water obtained from a Millipore Synergy 185 water purifier was used in the preparation of all samples.

Preparation of Calcium Nitrate and Phosphoric Acid Solutions and LLC Thin Films: $\mathrm{C}_{12} \mathrm{EO}_{10}(2.000 \mathrm{~g})$ was added to water $(7.0 \mathrm{~mL})$ in a pre-cleaned and dried vial. The mixture was then placed on a magnetic stirrer and stirred for 30 min to ensure homogenization. The appropriate amount of calcium nitrate (the mass depends on the intended concentration) was then added to the mixture, which was stirred for another 30 min before the required amount of phosphoric acid was finally added to the mixture. In all samples the CaN/PA molar ratio was kept at 1.67 (the ratio of $\mathrm{Ca} / \mathrm{P}$ in calcium hydroxyapatite). The solution was stirred for a further $10 \mathrm{~h}$ to ensure homogeneous mixing. The resulting clear solution remained clear indefinitely due to the high acidity of the media $(\mathrm{pH} \approx 0.73)$. Thin films of various compositions were formed in their LLC phases upon spin-coating of substrates. The exact numbers, in grams, of each of the precursors used in the preparations are tabulated in Table 2).

Table 2. Initial compositions of the samples used in this investigation.

\begin{tabular}{lccc}
\hline CaN/PA mol ratio $^{[a]}$ & $P A[g]$ & CaN $[\mathrm{g}]$ & $\mathrm{C}_{12} \mathrm{E}_{10}[\mathrm{~g}]$ \\
\hline $2.5: 1.5$ & 0.552 & 1.886 & 2.000 \\
$3.4: 2(\mathrm{~A})$ & 0.736 & 2.514 & 2.000 \\
$4.3: 2.5$ & 0.921 & 3.142 & 2.000 \\
$5: 3$ & 1.105 & 3.499 & 2.000 \\
$5.9: 3.5(\mathrm{~B})$ & 1.289 & 4.083 & 2.000 \\
$6.7: 4$ & 1.473 & 4.665 & 2.000 \\
$8: 4.5$ & 1.657 & 5.248 & 2.000 \\
$8.4: 5(\mathrm{C})$ & 1.841 & 5.833 & 2.000
\end{tabular}

[a] Molar ratios are given relative to the surfactant $C_{12} E_{10} . A, B$ and $C$ are specific samples investigated in detail.

Synthesis of Transparent Mesoporous Calcium Hydroxyapatite Thin Films: After homogenizing for $24 \mathrm{~h}$, the above solutions were spin-coated at $5000 \mathrm{rpm}$ over pre-cleaned $75 \mathrm{~mm} \times 25 \mathrm{~mm}$ glass microscope slides to obtain LLC thin films. To avoid the formation of side-products that could inhibit the synthesis, the films were immediately calcined at temperatures in the range $300-600{ }^{\circ} \mathrm{C}$ in a pre-heated oven. After placing the samples in an oven, the temperature was set to $100{ }^{\circ} \mathrm{C}$ and was then slowly increased to the desired temperature at a rate of $1.0^{\circ} \mathrm{C} / \mathrm{min}$ and then kept at the specified final temperature for $1 \mathrm{~h}$ to obtain the transparent mesoporous 
thin films. Samples A, B and C were produced in large quantities to collect PXRD and $\mathrm{N}_{2}$-sorption data.

Sample Preparation and Instrumentation: To obtain TEM images, the calcined films were carefully scraped from the glass substrate and ground for approximately $20 \mathrm{~min}$ in a mortar using a small amount of pure ethanol and then transferred to a vial. Then the vial containing the mixture was subjected to ultrasound for $30 \mathrm{~min}$ in ethanol to obtain a well-dispersed solution. The well-dispersed solutions were later drop-cast onto a hole-carbon support film TEM grid and immediately dried under a powerful light for $10 \mathrm{~min}$ to prevent re-aggregation of the dispersed particles. The samples were imaged by using a JEOL JEM $2100 \mathrm{~F}$ microscope at an operating voltage of $200 \mathrm{kV}$. For the $\mathrm{N}_{2}$-sorption and PXRD measurements, around 200 glass slides bearing transparent mesoporous $\mathrm{Ca}_{10}\left(\mathrm{PO}_{4}\right)_{6}(\mathrm{OH})_{2}$ films calcined at $300{ }^{\circ} \mathrm{C}$ were scraped to collect around $60 \mathrm{mg}$ of powder, which was used for the first $\mathrm{N}_{2}$-sorption and XRD measurements. After the first measurements, the same powder was heated to the subsequent temperature $\left(400{ }^{\circ} \mathrm{C}\right.$ and then finally $500{ }^{\circ} \mathrm{C}$ ) for the next sorption and PXRD measurements. The $\mathrm{N}_{2}(77.4 \mathrm{~K})$ sorption measurements were performed with a TriStar 3000 automated gas adsorption analyser (Micrometrics) in a relative pressure range, $P / P_{0}$, of $0.01-0.99$. To provide high accuracy and precision in the determination of $P / P_{0}$, the saturation pressure $P_{0}$ was measured over $120 \mathrm{~min}$ intervals. The powder samples, which were obtained by scraping approximately 200 glass slides bearing the films, were dehydrated under a vacuum (ca. 10 $0^{-2}$ Torr) for $3 \mathrm{~h}$ at $250{ }^{\circ} \mathrm{C}$ before measuring in order to remove adsorbed water and volatile species from the pores. The $\mathrm{N}_{2}$-sorption measurements were performed by evacuating the chamber at a pressure of 10 Torr under a vacuum of $150 \mu \mathrm{m} \mathrm{Hg}$ for $1 \mathrm{~h}$. Both a leak test and out-gas test were performed at 120 and $180 \mathrm{~s}$, respectively. The whole period of measurement lasted about $9 \mathrm{~h}$, after which the sample was removed from the tube and then heated again to the subsequent temperature. The PXRD measurements were performed with a Rigaku Miniflex diffractometer equipped with a high power $\mathrm{Cu}-K_{\alpha}$ source operating at $30 \mathrm{kV}$ and $15 \mathrm{~mA}$. The same samples used in the $\mathrm{N}_{2}$ sorption measurements were also used for the XRD measurements. For the SEM measurements, a small portion of the film was scraped from the glass substrate and placed over carbontape-covered aluminium SEM sample holders for imaging and EDX measurements. The SEM data were collected with a ZEISS EVO-40 microscope operating at $15 \mathrm{kV}$ and the same microscope and Bruker AXS XFlash detector 4010, respectively. The FTIR measurements were either performed by coating the samples over Si wafers (for the fresh samples, and samples heated between room temp. and $200^{\circ} \mathrm{C}$ ) or by preparing $\mathrm{KBr}$ pellets (for calcined samples). The FTIR spectra were collected with a Bruker Tensor 27 model FTIR spectrometer equipped with a Digi Tect TM DLATGS detector with a resolution of $4.0 \mathrm{~cm}^{-1}$ in the range $400-4000 \mathrm{~cm}^{-1}$.

\section{Acknowledgments}

E. T. thanks the Islamic Development Bank (IDB) for an M. Sc. scholarship. Ö. D. is a member of the Science Academy, Istanbul, Turkey.

Keywords: Mesoporous materials - Thin films · Liquid crystals · Surfactants · Calcium

[1] C. Albayrak, N. Özkan, Ö. Dag, Langmuir 2011, 27, 870-873.
[2] C. Albayrak, A. Cihaner, Ö. Dag, Chem. Eur. J. 2012, 18, 4190-4193.

[3] K. Binder, J. Horbach, R. Vink, A. de Vigiliis, Soft Matter 2008, 4, 15551568.

[4] P. Chi, Z. Wang, B. H. Li, A. C. Shi, Langmuir 2011, 27, 11683-11689.

[5] C. Cramer, T. Cramer, F. Kremer, R. Stannarius, J. Chem. Phys. 1997, 106, 3730-3742.

[6] L. M. Wang, F. He, R. Richert, Phys. Rev. Lett. 2004, 92, 095701-4.

[7] Ö. Çelik, Ö. Dag, Angew. Chem. Int. Ed. 2001, 40, 3799-3803; Angew. Chem. 2001, 113, 3915.

[8] G. Barım, C. Albayrak, E. Yılmaz, Ö. Dag, Langmuir 2014, 30, 6938-6945.

[9] C. Karakaya, Y. Türker, Ö. Dag, Adv. Funct. Mater. 2013, 23, 4002-4010.

[10] C. Karakaya, Y. Türker, C. Albayrak, Ö. Dag, Chem. Mater. 2011, 23, 30623071.

[11] R. Z. LeGores, Chem. Rev. 2008, 108, 4742-4753.

[12] I. Soten, G. A. Ozin, J. Mater. Chem. 1999, 9, 703-710.

[13] B. J. Melde, A. Stein, Chem. Mater. 2002, 14, 3326-3331.

[14] T. T. Morgan, H. S. Muddana, E. I. Altinoglu, S. M. Rouse, A. Tabakovic, T. Tabouillot, T. J. Russain, S. S. Shanmugavelandy, P. J. Butler, P. C. Eklund, J. K. Yun, M. Kester, J. H. Adair, Nano Lett. 2008, 8, 4108-4115.

[15] M. Y. Ma, Y. J. Zhu, L. Li, S. W. Cao, J. Mater. Chem. 2008, 18, 2722-2727.

[16] Y. Cai, H. Pan, X. Xu, Q. Hu, L. Li, R. Tang, Chem. Mater. 2007, 19, $3081-$ 3083.

[17] T. Matsumoto, M. Okazaki, A. Nakahira, J. Sasaki, H. Egusa, T. Sohmura, Curr. Med. Chem. 2007, 14, 2726-2733.

[18] M. A. Rauschmann, T. A. Wichelhaus, V. Stirnal, E. Dingeldein, L. Zichner, R. Schnettler, V. Alt, Biomaterials 2005, 26, 2677-2684.

[19] K. Lin, Y. Zhou, Y. Zhou, H. Qu, F. Chen, Y. Zhu, J. Chang, J. Mater. Chem. 2011, 21, 16558-16565.

[20] D. Li, Y. Zhu, Z. Liang, Mater. Res. Bull. 2013, 48, 2201-2204.

[21] J. Yao, W. Tjandra, Y. Z. Chen, K. C. Tam, J. Ma, B. Soh, J. Mater. Chem. 2003, 13, 3053-3057.

[22] S. Sadasivan, D. Khushalani, S. Mann, Chem. Mater. 2005, 17, 2765-2770.

[23] T. Long, Y.-P. Gou, S. Tang, Y.-J. Guo, Z.-A. Zhu, RSC Adv. 2014, 4, 1181611825.

[24] S. Bose, S. K. Saha, Chem. Mater. 2003, 15, 4464-4469.

[25] J.-M. Tarasco, M. Armand, Nature 2001, 414, 359-367.

[26] N.-S. Choi, Z. Chen, S. A. Freunberger, X. Ji, Y.-K. Sun, K. Amine, G. Yushin, L. F. Nazar, J. Chao, P. G. Bruce, Angew. Chem. Int. Ed. 2012, 51, $9994-$ 10024; Angew. Chem. 2012, 124, 10134.

[27] R. L. Kerr, S. A. Miller, R. K. Shoemaker, B. J. Elliott, D. L. Gin, J. Am. Chem. Soc. 2009, 131, 15972-15973.

[28] F. Jiao, K. M. Shaju, P. G. Bruce, Angew. Chem. Int. Ed. 2005, 44, 65506553; Angew. Chem. 2005, 117, 6708.

[29] H. C. Shum, A. Bandyopadhyay, S. Bose, D. A. Weitz, Chem. Mater. 2009, $21,5548-5555$

[30] J. Zhang, M. Fujiwara, Q. Xu, Y. Zhu, M. Iwasa, D. Jiang, Microporous Mesoporous Mater. 2008, 111, 411-416.

[31] N. Ikawa, H. Hori, T. Kimura, Y. Oumi, T. Sano, Langmuir 2008, 24, 1311313120.

[32] Y. T. Huang, M. Imura, Y. Nemoto, C.-H. Cheng, Y. Yamauchi, Sci. Technol. Adv. Mater. 2011, 12, 045005-6.

[33] H. Wang, L. Zhai, Y. Li, T. Shi, Mater. Res. Bull. 2008, 43, 1607-1614.

[34] B. P. Bastakoti, M. Inuoe, S.-I. Yusa, S.-H. Liao, K. C.-W. Wu, K. Nakashima, Y. Yamauchi, Chem. Commun. 2012, 48, 6532-6534.

[35] G. A. Ozin, N. Varaksa, N. Coombs, J. E. Davies, D. D. Petrovic, M. Ziliox, J. Mater. Chem. 1997, 7, 1601-1607.

[36] M. Uota, H. Arakawa, N. Kitamura, T. Yoshimura, J. Tanaka, T. Kijima, Langmuir 2005, 21, 4724-4728.

[37] M. Kanapathipillai, Y. Yusufoglu, A. Rawal, Y.-Y. Hu, C.-T. Lo, P. Thiyagarajan, Y. E. Kalay, M. Akinc, S. Mallapragada, K. Schmidt-Rohr, Chem. Mater. 2008, 20, 5922-5932.

[38] W. He, P. Kjellin, F. Currie, P. Handa, C. S. Knee, J. Bielecki, L. R. Wallenberg, M. Andersson, Chem. Mater. 2012, 24, 892-902.

[39] Q. He, L. Pan, Y. Wang, F. C. Meldrum, Cryst. Growth Des. 2015, 15, 723731.

[40] K. M. McGrath, D. M. Dabbs, N. Yao, I. A. Aksay, S. M. Gruner, Science 1997, 277, 552-556.

[41] E. Tunkara, C. Albayrak, E. O. Polat, C. Kocabas, Ö. Dag, ACS Nano 2014, 8, 11007-11012.

[42] C. Albayrak, G. Barım, Ö. Dag, J. Colloid Interface Sci. 2014, 433, 26-33. 
[43] C. Albayrak, A. M. Soylu, Ö. Dag, J. Colloid Interface Sci. 2010, 341, 109116.

[44] W. W. Rudolph, Dalton Trans. 2010, 39, 9642-9653.

[45] Y. Fadeeva, L. P. Safonova, I. Persson, Phys. Chem. Chem. Phys. 2010, 12, 8977-8984.

[46] A. C. Tas, J. Am. Ceram. Soc. 2009, 92, 2907-2912.
[47] Ö. Dag, O. Samarskaya, C. Tura, A. Günay, Ö. Çelik, Langmuir 2003, 19, 3671-3676.

[48] M. Corno, C. Busco, B. Civalleri, P. Ugliengo, Phys. Chem. Chem. Phys. 2006, 8, 2464-2472.

Received: September 30, 2015

Published Online: December 2, 2015 